\title{
Fostering Stance-Taking as a Sustainable Goal in Developing EFL Students' Academic Writing Skills: Exploring the Effects of Explicit Instruction on Academic Writing Skills and Stance Deployment
}

\author{
Lu Zhang (D) and Lawrence Jun Zhang *(D) \\ Faculty of Education and Social Work, The University of Auckland, Auckland 1023, New Zealand; \\ zhang.lu@auckland.ac.nz \\ * Correspondence: lj.zhang@auckland.ac.nz; Tel.: +64-9-6238899 (ext. 48750)
}

check for updates

Citation: Zhang, L.; Zhang, L.J. Fostering Stance-Taking as a Sustainable Goal in Developing EFL Students' Academic Writing Skills: Exploring the Effects of Explicit Instruction on Academic Writing Skills and Stance Deployment. Sustainability 2021, 13, 4270. https://doi.org/10.3390/su13084270

Academic Editors: Xuesong (Andy) Gao and Mairin Hennebry-Leung

Received: 12 March 2021

Accepted: 8 April 2021

Published: 12 April 2021

Publisher's Note: MDPI stays neutral with regard to jurisdictional claims in published maps and institutional affiliations.

Copyright: (c) 2021 by the authors. Licensee MDPI, Basel, Switzerland. This article is an open access article distributed under the terms and conditions of the Creative Commons Attribution (CC BY) license (https:/ / creativecommons.org/licenses/by/ $4.0 /)$.

\begin{abstract}
Effective stance-taking is considered as a crucial skill for successful academic writing and sustainable development of writing scholarship. However, student writers often encounter difficulties in this aspect. Scholars have thus called for explicit instruction to develop students' academic writing ability as a sustainable goal. Learning stance-taking is a particularly relevant area of intensive interest among writing scholars. Yet, few empirical studies have been conducted to examine its effectiveness on students' academic writing quality and stance deployment. To fill this gap, a quasi-experimental research was conducted with 46 undergraduate students in a Chinese university, who were randomly assigned to two conditions: a treatment group and a comparison group. The treatment group received an eight-week explicit stance instruction, while the comparison group received curriculum-based writing instruction at the same time. Academic texts were collected both prior to and after the period of intervention. Results revealed that the treatment group outperformed the comparison group in the post-test in terms of academic writing quality and stance performance. Their writing also exhibited changes in the frequencies of an array of stance types deployed (e.g., proclaim: pronounce, proclaim: endorse, entertain, attribute), indicating their enhanced understanding of stance and improved competence of mitigation and integrating external voices for better academic writing. Implications for writing instruction are discussed.
\end{abstract}

Keywords: authorial stance; explicit instruction; academic writing; Chinese leaners of English

\section{Introduction}

Authorial stance is defined as the way that a writer conveys personal evaluations toward the subject matter under discussion and this phenomenon has received increasing research attention [1-4]. During the recent decade, extensive research has shown that skilled academic writers are able to strategically present authorial stance that contributes to critical evaluation, reader solidarity, and persuasive argumentation [5-10]. Taking an effective stance is thus gradually considered as a crucial skill for both professional academics and student writers for achieving successful writing and sustainable development of writing scholarship $[11,12]$. However, many existing studies have revealed that student writers, especially L2 student writers, often encounter difficulties in stance-taking [3,13,14]. For instance, student writing is frequently found to be single-voiced, with strong commitments, authorial detachment, or without acknowledging alternative views $[3,9,13,15,16]$. These features are regarded as less strategic in interpersonal positioning and dialogic alignment with readers to the detriment of writing quality [17].

Noticing the importance of stance and students' difficulties, many scholars postulated that students may not be well-prepared by the academic writing instruction they received [18-22]. As Wingate [11] argued, stance features in academic writing are rarely 
made explicit to students, which may result in the lack of awareness and incompetence in stance performance. Driven by this incentive, many scholars have advocated for explicit instruction of stance in the writing classroom, to develop students' sustainable ability of stance-taking for better academic writing $[7,18,19,23,24]$. For instance, Crosthwaite and Jiang [7] recommended that explicit instruction of stance features should be incorporated as a crucial part in English for Academic Purposes (hereafter EAP) programs at the university level. Yet, insufficient intervention studies have been carried out to evaluate its effectiveness. To fill this gap, the current study investigated the effects of explicit stance instruction, framed within the Engagement system from a theoretical perspective of dialogism, on students' stance deployment and academic writing quality in an EFL context at the tertiary level. Addressing this gap would shed some light on the effectiveness of explicit instruction in fostering students' stance-taking for successful academic writing and sustainable development of writing scholarship.

\section{Theoretical Perspective and Review of Literature}

\subsection{Dialogic Perspective and Stance-Taking}

The theoretical perspective of dialogism views all utterances as fundamentally dialogic and social interactive [25]. This theory is widely used to address social interactions involved in written discourses, which provides the theoretical foundation for the course design in this study. The dialogic lens views the writer as engaging in a living heteroglossia, in which he or she dynamically interacts with referred voices that reflect shared or alien positions in the social and disciplinary community, and at the same time responds to the putative answers from readers [25]. Writers' stance-taking behaviors are the furrowed traces of the triangular dialogic interaction between writers, prior texts, and prospective audience $[11,26]$. From the dialogic perspective, we use the term "stance" following White [27], Du Bois [28], and Lancaster [9] to refer to the ways that writers convey personal evaluations while positioning them with respect to alternative views and interacting with putative readers. In academic contexts, stance is mostly realized through the linguistic markers a writer adopted in expressing personal position-taking, such as by showing the writer as standing with the value position through intensifying or concurring tokens (e.g., indeed, greatly, as we know), as standing against it through counter-expectancy markers (e.g., but, however), as undecided by using modal expressions (e.g., may, could), or as neutral by using reporting verbs (e.g., X says), among others. Through the appropriate use and configuration of such resources, a writer is able to explicitly present her or his viewpoint, critically evaluate opinions of others, claim solidarity with putative readers, and ultimately construct a text that is considered persuasive [29].

To better inform students, we drew on the Engagement system as a typology of stance resources [27,30]. Figure 1 presents an overview of the Engagement system with representative stance markers. The framework firstly classifies utterances into monogloss and heterogloss. Monoglossic or single-voiced utterance refers to the utterance when the writer makes no overt reference to other viewpoints and barely asserts the proposition as a fact, thus ignoring the dialogic possibilities (e.g., Different cultures have caused many conflicts.). Heterogloss, or multi-voiced utterance, overtly incorporates other voices or acknowledges potentially different viewpoints (e.g., Sociologists claim that different cultures have caused many conflicts.). Within the heteroglossic scope, utterances can be further divided into dialogic contraction and expansion according to the interpersonal functionality of available resources. The difference between the two heteroglossic orientations lies in the degree to which the engagement options are used to reduce the dialogic possibilities (contraction) or are more open for dialogic positions and alternative voices (expansion). 


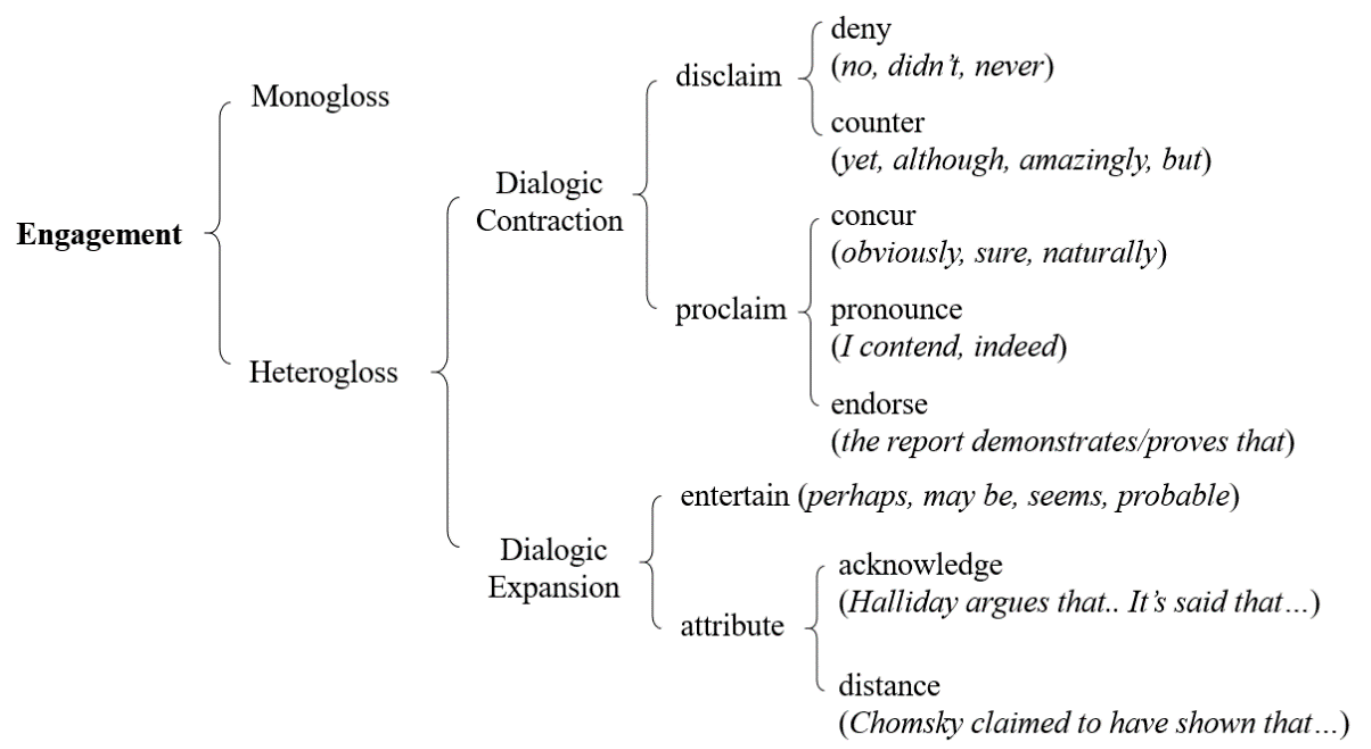

Figure 1. The Engagement system adapted from Martin and White (2005).

Dialogic contraction includes two categories: disclaim and proclaim. Typical linguistic resources working to contract dialogic space include denials (e.g., not, never), adversative or counter-expectancy markers (e.g., but, however, on the contrary), intensifying adverbs or formulations (e.g., indeed, greatly, we must), and concurring formulations (e.g., obviously, as we know), among others. Dialogic expansion consists of two categories: entertain and attribute. The utterance of entertain opens up the dialogic space by indicating the authorial position is one of a number of possible positions. The formulation of attribute disassociates the proposition from the authorial voice by attributing it to external sources. Resources for expanding dialogic spaces typically represented via modal expressions (e.g., may, could, possible), appearance-based verbs (e.g., seem), mental or reporting verbs (e.g., I think, $\mathrm{X}$ says/argues), and adverbial adjuncts (e.g., according to).

The dialogic perspective and the framework of Engagement have been adopted in a plethora of empirical studies on stance features by virtue of their power in elucidating the nuanced differences in dialogic negotiations in argumentation [9,24,31]. More importantly for this study, their pedagogical potential has been recommended and preliminarily proved in empirical investigations [6,19,23,32-34]. As Chang and Schleppegrell [19] argued, the Engagement system has the potential to serve as a powerful instructional tool in supporting advanced academic writing. However, few intervention studies have been conducted that were embarked from this perspective.

\subsection{Explicit Instruction of Authorial Stance}

Of the existing literature on stance, student writers, especially L2 student writers, are often found to be less strategic in stance-taking for establishing persuasive argumentation. For instance, texts of advanced L2 student writers often contain noticeable stance features such as monoglossic, subjective without acknowledging alternative views, over-relying on assertive stance markers, and authorial voice detached from critical evaluation $[3,13,15,16]$. The difficulties in stance-taking that L2 students have confronted have become a severe challenge to the detriment of their writing quality and future scholarship [17-19]. This is an urgent problem to be solved, as there is an increasing demand for advanced L2 students to become successful academic writers, especially in the social sciences disciplines that call for authorial establishment.

Many scholars have speculated that students were lack of stance awareness in the learning context, and thus recommend the inclusion of explicit instruction of stance in the writing classroom to develop L2 writers' stance-taking skills for better writing outcomes $[7,18-21,35,36]$. 
In the light of language learning theories, teaching that targets the mappings of linguistic forms, functions, and contexts, ranges on an explicit-implicit continuum, for which the determining variable is noticing $[37,38]$. According to Schmidt [38], noticing is consciously paying attention to the target language system or mappings of form-function-context. Norris and Ortega [39] summarized that explicit instructional treatment involves either rule explanation or directions for learners to attend to target forms, while the instruction with neither of them is considered implicit. The rule explanation in explicit instruction, directly getting learners to notice the target forms, is often argued and proved in previous literature as facilitative, or even necessary, for adult learners to acquire target language features [40-43]. It is also frequently adopted in teaching of genre knowledge and is found to be effective in raising students' genre awareness for better academic writing [44-47]. Pessoa and her colleagues [42] further argued that explicit writing instruction can help close the gap between novice and experienced academic writers, while experienced writers also gain from this way of teaching.

Given the calls for explicit stance instruction, several intervention studies have been conducted recently that present positive effects on various aspects of stance deployment. For instance, Chang and Schleppegrell [19] conducted explicit instruction of stance with seven Mandarin-speaking doctoral students by using a web-based stance corpus, Authorial stance database (http:/ / web.ntnu.edu.tw/ peichinchang/ (accessed on 28 August 2018)), designed based on Swales' [48] rhetorical moves and the Engagement system [30]. After three treatment sessions, learners showed improvement in the accuracy of stance deployment and became more purposeful in deploying stance to fulfil rhetorical purposes, suggesting increased awareness of stance. However, they still performed less satisfying in terms of expansive stances and overall patterns, which suggested that these aspects need more pedagogical attention and may take time to develop. Chang and Schleppegrell further argued that the ability to produce an effective rhetorical move structure might scaffold learners' stance-taking practices. Crosthwaite and Jiang [7] evaluated the longitudinal development of stance features in L2 essay and report writing from an EAP course at a Hong Kong university. Three weeks of explicit stance instruction were conducted based on Hyland's [2] model of interactional metadiscourse (i.e., hedges, boosters, self-mention, and attitude markers), in which students were presented with annotated examples of stance features in essay and report exemplars, with emphasis on the importance of these features to successful academic writing. Results showed significant long-term variation in student writing with a rise in the use of hedges and an overall reduction in the use of boosters and self-mention, indicating that students were more careful, less polarizing, and less personal when conveying stance over time, which earned higher grades from teachers. Fordyce [37] further compared explicit stance instruction with implicit instruction in terms of the immediate and long-term effects with EFL learners at the university level. The four-session interventions were constructed based on authentic texts with rich resources of epistemic stance. Results indicated that explicit intervention was considerably more effective than the implicit one in both the immediate and long-term for the use of most of the targeted stance forms and stance variety. Fordyce [37] also advocated to cover multiple levels of language use in context when instructing learners on authorial stance, as authorial stance can be framed in the functional area of language and serves a rhetorical or communicative purpose in the context.

Although limited in number, these intervention studies suggest that explicit teaching of stance facilitates student writers' awareness and improves the variety and frequency of targeted stance resources. These empirical studies also provide empirical evidence for the pedagogical potential of the Engagement system in the teaching of stance for L2 academic writers. Additionally, there is a tendency to incorporate genre knowledge into the teaching of stance for academic writing, as Charles [49] advocated that an approach which makes a connection between rhetorical purposes and specific lexico-grammatical choices may be beneficial for students' learning of writing. Furthermore, these studies have 
drawn on authentic writing materials in the target genre to provide guidance and practice opportunities for student writers, which is insightful for the current course design.

However, previous intervention studies reported changes only within the treatment group and did not involve a comparison group, which may call into question of the effectiveness of explicit instruction. It is actually beneficial to compare the effects of explicit stance instruction with curriculum-based instruction to investigate the role and time allocation of teaching stance, as the EAP programs may also generate positive effects on stance-taking [7]. Moreover, examination of the teaching effects on both academic writing quality and stance deployment could engender insights on the role of stance intervention in teaching writing, which had rarely come into sight in previous studies. Informed by these gaps, we conducted a quasi-experimental research investigating into the effects of explicit stance instruction, framed within the Engagement system, on students' academic writing quality and stance deployment in an EFL context at the tertiary level. Three research questions are addressed as follows:

(1) Did explicit stance instruction have any impact on students' overall writing quality?

(2) Did explicit stance instruction have any impact on students' overall stance performance?

(3) Did explicit stance instruction have any impact on students' deployment of stance features?

\section{Methods}

\subsection{Participants}

A total of 46 English-major undergraduates in Year 3 from two intact classes were recruited from a medium-ranking university in China through a convenience sampling strategy. They were randomly assigned into two conditions: a treatment group and a comparison group. The treatment group involved 24 students, in which $87.5 \%$ were female $(n=21)$ and $12.5 \%$ were male $(n=3)$. The average age was $20.79(S D=0.977)$. The comparison group included 22 students, in which $72.7 \%$ were female $(n=16)$ and $27.3 \%$ were male $(n=6)$. The average age was $20.86(S D=0.774)$. At the time of data collection, all the students were enrolled in a required course on EAP writing focusing on forming academic argumentation.

\subsection{Writing Intervention}

The writing intervention in this study was designed mainly based on the Engagement system [30], with modification in consideration of better communicating with participants. Table 1 presents an overview of the writing intervention conducted in the treatment group, including time, instruction content and materials used. In the treatment group, the intervention was provided once a week for a $45 \mathrm{~min}$ session and lasted for eight weeks. The interventional content could be divided into two parts. Firstly, students were provided with the knowledge about the genre of academic introduction, drawing on Swales' [48] model of rhetorical moves, create a Research Space (hereafter CARS) (i.e., establishing a territory, establishing a niche and presenting the present work). As previous studies indicated $[19,49,50]$, students should be encouraged to understand the connection between rhetorical purposes and linguistic features. After recognizing the rhetorical purposes, students were provided with stance instruction operationalized according to Norris and Ortega's [39] description of explicit instruction. The explicit rule explanation was designed based on the Engagement system to directly raise learners' consciousness of target stance features and dialogical functions. 
Table 1. Explicit stance instruction for the treatment group.

\begin{tabular}{|c|c|c|}
\hline Time & Instructional Content & Materials \\
\hline Week 1 & $\begin{array}{l}\text { How to introduce your own research? Three } \\
\text { rhetorical moves in introduction }\end{array}$ & $\begin{array}{l}\text { Academic writing for } \\
\text { graduate students [51] }\end{array}$ \\
\hline Week 2 & $\begin{array}{l}\text { Key concepts in academic writing: } \\
\text { (1) Dialogic nature of writing } \\
\text { (2) Authorial stance }\end{array}$ & \multirow{6}{*}{$\begin{array}{c}\text { Texts from Authorial Stance } \\
\text { Database }\end{array}$} \\
\hline Week 3 & $\begin{array}{c}\text { Stance types: } \\
\text { Non-argumentative and Argumentative } \\
\text { (Monogloss and heterogloss) }\end{array}$ & \\
\hline Week 4 & $\begin{array}{c}\text { Stance types: } \\
\text { High-argumentative (Dialogic contraction) }\end{array}$ & \\
\hline Week 5 & $\begin{array}{c}\text { Stance types: } \\
\text { Low-argumentative (Dialogic expansion) }\end{array}$ & \\
\hline Week 6 & Review of stance types & \\
\hline Week 7 & Stance in experts' writing & \\
\hline Week 8 & $\begin{array}{l}\text { How to improve your argumentation? } \\
\text { Reflection on pre-test writing }\end{array}$ & \\
\hline
\end{tabular}

Inspired by Chang and Schleppegrell's [19] writing intervention, the technical terms in the Engagement system were simplified and substituted by a set of graduated terms to better support students' learning. Multi-level text materials were used in the instruction and practices, which are authentic introductions from published journal articles selected from Chang and Schleppegrell's [19] database, Authorial stance database. The specific instructional activities used in the treatment group included:

- metalinguistic instruction on the use of stance and its dialogic effects;

- $\quad$ reading tasks to draw attention to stance use at multiple levels in the texts;

- $\quad$ tasks on identifying different stance types;

- peer-evaluation of stance deployment in pre-test writing.

The genre instruction was also provided in the comparison group at the same period of time with the aim of ruling out the genre factor that might affect students' writing performance and assuring that the possible effects of intervention were due to explicit stance instruction. During the intervention period, the comparison group received curriculumbased writing instruction which focused on building successful academic writing.

\section{Teacher Training}

The two groups were instructed by the same teacher who was voluntarily recruited from the qualified instructors that were responsible for teaching the writing course during the research period. The teacher was invited to attend three training sessions prior to the period of writing intervention ( $2 \mathrm{~h}$ per session), which introduced the instructional content and the focus of the pre-planned classroom activities. After each training session, the teacher engaged in critical reflection on the instructional content and had the opportunity to propose questions and practical constraints they might be concerned about. We worked together to reach possible solutions, clarifications, or modifications of instructional content and process, if necessary. The teacher was informed that classroom observations might be conducted in both groups during the period of writing intervention, to ensure teaching fidelity and that he did not implement the training package in the comparison group.

\subsection{Pre-and Post-Writing}

The introductory sections of theses were used to investigate students' stance deployment and writing performance. Sawaki [14] argued that the introductory section is 
featured with the author's evaluative voices with "careful construction of intertextual link" to establish the research space (p. 83). Milagros del Saz Rubio [52] also emphasized that introductions pose a challenge for non-native writers as they prepare the research ground by referring to previous studies and project themselves for the first time in this section. At the tertiary level in China, English majors are required to write a 5000-word final thesis in English with a structure of a research article, that is, to include sections of Introduction, Literature Review, Methods, Results, and Discussion (IMRD). Students are expected to propose research questions, have scientific reasoning and methods based on the literature review, and display data analysis and interpretation.

In this study, students from the two groups were invited to complete after-class writing assignments prior to and after the writing intervention. They were required to write a 300-word introduction section for their thesis in the near future. Students were entitled to choose their own topics according to their academic interests within the scope required by official curriculum. The written texts were collected one week later with their consent. The post-test writing was a revised version of students' own pre-test writing with no change in topic. Due to the after-class nature of the assignments, all the collected written texts firstly went through a procedure of plagiarism checking by using Turnitin (http:/ / www.turnitin.com/ accessed on 28 August 2018), which is a widely used online plagiarism prevention and detection system $[53,54]$. No text was removed due to plagiarism as the similarity indices, excluding quotes, ranged from $0 \%$ to $25 \%$, which was acceptable according to the requirements for thesis in the university where the current study was conducted. The topics of written texts fell into five categories: English literary studies, linguistics, English-Chinese translation, comparison of Chinese and western culture, and English language teaching. Table 2 presents a summary of the written texts collected prior to and after the writing intervention, including the total number and average length of written texts, and the number of texts for each topic category.

Table 2. Information of students' written texts in pre- and post-tests.

\begin{tabular}{|c|c|c|c|c|c|c|c|}
\hline \multirow{2}{*}{ Group } & \multirow{2}{*}{$\begin{array}{c}\text { Number of } \\
\text { Texts }\end{array}$} & \multirow{2}{*}{$\begin{array}{l}\text { Mean Length } \\
\text { of Texts (SD) }\end{array}$} & \multicolumn{5}{|c|}{ Topics (n \%) } \\
\hline & & & Literature & Linguistics & Translation & Culture & Teaching \\
\hline \multirow[b]{2}{*}{ Treatment } & \multirow[b]{2}{*}{24} & $\begin{array}{c}\text { Pre: } 341.13 \\
(62.64)\end{array}$ & \multirow{2}{*}{$\begin{array}{c}10 \\
(37.5 \%)\end{array}$} & \multirow{2}{*}{$\begin{array}{c}0 \\
(0 \%)\end{array}$} & \multirow{2}{*}{$\begin{array}{c}3 \\
(12.5 \%)\end{array}$} & \multirow{2}{*}{$\begin{array}{c}9 \\
(33.33 \%)\end{array}$} & \multirow{2}{*}{$\begin{array}{c}2 \\
(8.33 \%)\end{array}$} \\
\hline & & $\begin{array}{c}\text { Post: } 325.42 \\
(58.70)\end{array}$ & & & & & \\
\hline \multirow{2}{*}{ Comparison } & \multirow{2}{*}{22} & $\begin{array}{c}\text { Pre: } 322.68 \\
(71.81)\end{array}$ & \multirow{2}{*}{$\begin{array}{c}8 \\
(36.36 \%)\end{array}$} & \multirow{2}{*}{$\begin{array}{c}3 \\
(13.64 \%)\end{array}$} & \multirow{2}{*}{$\begin{array}{c}5 \\
(22.73 \%)\end{array}$} & \multirow{2}{*}{$\begin{array}{c}5 \\
(22.73 \%)\end{array}$} & \multirow{2}{*}{$\begin{array}{c}1 \\
(4.55 \%)\end{array}$} \\
\hline & & $\begin{array}{c}\text { Post: } 327.64 \\
(57.96)\end{array}$ & & & & & \\
\hline
\end{tabular}

Each text was evaluated in terms of overall quality, overall stance performance, and stance deployment. Firstly, the overall quality of each text was evaluated by using the analytic scoring rubric, the ESL composition profile [55]. The analytic scoring rubric measures five aspects of writing performance: content $(30 \%, 13-30)$, organization $(20 \%, 7-20)$, vocabulary $(20 \%, 7-20)$, language use $(25 \%, 5-25)$, and mechanics $(5 \%, 2-5)$. Each aspect has four scoring levels with indicators and corresponding scores for each level. Two raters participated in the scoring of texts. Rater one held a PhD degree in English teaching and the first author was the second rater. Both raters held master's degrees in applied linguistics and had experience in English teaching. A training session was conducted before independent scoring. To avoid potential rating bias, a third person other than the two raters rearranged the writing texts before scoring, with the participants' identification codes and grouping information temporarily removed. The inter-rater reliability was $r=0.88, p<0.001$, and the intra-rater coefficients for the two raters were $r=0.89$ and 
0.87 , respectively, $p<0.001$, indicating satisfactory reliability. The averaged overall scores marked by the two raters were used for statistical analysis.

Secondly, the overall stance performance was assessed by using a stance rating scale adapted from Chang [29] for evaluating students' research introductions. In the application of the rating scale, each text was first divided into three moves according to Swales' [48] CARS model of rhetorical moves. For each move (hereafter M1, M2, and M3), holistic scores were granted from 1 to 10 according to the indicators of stance features. See Appendix A for the stance rating scale. After a training session and discussion of discrepant instances, the two raters marked the written texts independently. The inter-rater reliabilities for stance scores of the three moves were $r=0.89,0.96$, and 0.93 , respectively, $p<0.001$. One month later, the two raters re-evaluated 27 pieces of written texts (30\% of the total number). The intra-rater coefficients for the two raters were $r=0.91$ and 0.92 , respectively, $p<0.001$. Inter-rater and intra-rater reliabilities were satisfactory. The final score for each move was the average of the scores given by the two raters. The overall stance score for each text was the sum of the corresponding stance scores of the three moves.

After the scoring procedure, two measures of stance deployment in each text were analyzed and calculated, including the frequencies of various stance types and diversity, that is, the number of different stance types applied. Each text was firstly coded according to an operationalized scheme adapted from the Engagement framework (see Appendix B), with the assistance of the software, Nvivo 12. We took each sentence as the unit of analysis and labeled it with the corresponding stance type according to the main clauses if different stance resources were applied in one sentence. Subordinate clauses were not coded separately in this study as they served as complements to the proposition mainly stated by the main clause $[9,16,19]$. To ensure the credibility and reliability of the coding procedure, Rater One was trained and invited to code 20 pieces of writing texts. The inter-coder agreement was $86.7 \%$. We randomly re-coded 30 texts two months later to avoid potential subjectivity. The intra-coder agreement was $89.3 \%$. Both reliabilities were acceptable. Based on the coding results, two measures of stance deployment, frequency and diversity, were then calculated. The frequency of each stance type was counted and transformed into standardized frequencies per 100 sentences. The total frequencies for dialogic contraction, dialogic expansion, and heterogloss were the sums of the frequencies of stance subtypes they composed.

\subsection{Procedures}

Prior to the writing intervention, all the student participants in both groups were provided with a workshop on pre-test writing in which they were informed of the requirements for thesis topic selection and writing introduction. Their topics were checked before they started to write. All the participants were asked then to complete a 300-word pre-test writing assignment and submit it electronically within one week. Participants were informed of the purpose of the study and their rights to withdraw at any time during the data collection period. Each participant was given an identification code for the purpose of anonymity and confidentiality. They were asked to use this code to label the text file they submitted.

During the intervention, participants in the treatment group received the 8-week writing intervention, while students in the comparison group received regular academic writing instruction based on the university curriculum. At the end of the writing intervention, students in both groups were asked to revise their own pre-test writing based on what they had learned and submit their updated version of introductions electronically within one week. In order to ensure participants in the comparison group were not disadvantaged, the teacher provided the same explicit stance instruction to the comparison group after the data collection procedure, and all resources used in the intervention were made available to the students. 


\subsection{Data Analysis}

Data collected from written texts were screened and cleaned. Missing values, outliers, and assumption of normality were examined before the data were subjected to statistical tests. All the scores, except for the M2 stance scores, were normally distributed. In terms of stance frequencies, the general categories of total contraction, total expansion, heterogloss, and monogloss, along with two stance subtypes (disclaim: counter and entertain), had normal distribution. The frequencies of the rest of stance subtypes, however, were non-normally distributed. Stance diversity was found normally distributed.

Independent samples $t$-tests were used to investigate the between-group differences prior to and after the writing intervention for normally distributed variables. Paired samples $t$-tests were applied to explore the differences within each group at different times. Cohen's $d$ was used to measure the effect size of the significant difference (small $=0.2$; medium $=0.5$; large $=0.8)[56,57]$. Mann-Whitney $U$ tests and Wilcoxon signed-rank tests were used as non-parametric alternatives to independent and paired-samples $t$-tests for the analysis of non-normal variables. The effect size estimate, $r$, was reported for Mann-Whitney $U$ tests and Wilcoxon signed-rank tests $($ small $=0.10$; medium $=0.30$; large $=0.50)[58]$.

\section{Results}

\subsection{Comparison of Baseline Conditions of the Two Groups in the Pre-Test}

\subsubsection{Overall Writing Scores and Stance Scores}

Table 3 reports the descriptive statistics of overall writing scores and stance scores, and results of independent samples $t$-tests. Results showed that there was no significant difference between the treatment group and the comparison group in terms of the overall writing scores, the overall stance scores, M1 and M3 stance scores, in the pre-test. MannWhitney $U$ test was conducted for M2 stance scores which was non-normally distributed, and found no significant difference between the two groups, $U=241.50, z=0.687, p=0.492$.

Table 3. Descriptive statistics and independent samples $t$-tests of writing scores between two groups in the pre-tests.

\begin{tabular}{|c|c|c|c|c|c|c|}
\hline & Group & $N$ & $M$ & $S D$ & $t$ & $p$ \\
\hline \multirow{2}{*}{$\begin{array}{c}\text { Overall } \\
\text { writing scores }\end{array}$} & Treatment & 24 & 68.65 & 8.17 & \multirow{2}{*}{1.346} & \multirow{2}{*}{0.185} \\
\hline & Comparison & 22 & 65.37 & 8.36 & & \\
\hline \multirow{2}{*}{$\begin{array}{c}\text { Overall } \\
\text { stance scores }\end{array}$} & Treatment & 24 & 11.46 & 4.89 & \multirow{2}{*}{1.108} & \multirow{2}{*}{0.274} \\
\hline & Comparison & 22 & 10.09 & 3.41 & & \\
\hline \multirow{2}{*}{ M1 stance ${ }^{1}$} & Treatment & 24 & 4.85 & 1.99 & \multirow{2}{*}{1.846} & \multirow{2}{*}{0.073} \\
\hline & Comparison & 22 & 4.00 & 1.05 & & \\
\hline \multirow{2}{*}{ M2 stance } & Treatment & 24 & 1.69 & 1.76 & & \\
\hline & Comparison & 22 & 1.14 & 0.35 & & \\
\hline \multirow{2}{*}{ M3 stance } & Treatment & 24 & 4.92 & 2.90 & \multirow{2}{*}{-0.047} & \multirow{2}{*}{0.963} \\
\hline & Comparison & 22 & 4.95 & 2.53 & & \\
\hline
\end{tabular}

${ }^{1}$ M1 stance $=$ Move 1 stance score.

\subsubsection{Stance Deployment}

Table 4 reports the descriptive statistics of variables of stance deployment that were in normal distribution, as well as corresponding results of independent samples $t$-tests. These variables include stance diversity, the frequencies of the general stance categories (i.e., total contraction, total expansion, monogloss, and heterogloss, and the frequencies of two stance subtypes (disclaim: counter and entertain). No significant difference was detected between the two groups in the pre-test. 
Table 4. Descriptive statistics and independent samples $t$-tests of stance deployment between two groups in the pre-test.

\begin{tabular}{|c|c|c|c|c|c|c|}
\hline & Group & $N$ & $M$ & $S D$ & $t$ & $p$ \\
\hline \multirow{2}{*}{ Stance diversity } & Treatment & 24 & 5.33 & 1.24 & \multirow{2}{*}{1.465} & \multirow{2}{*}{0.150} \\
\hline & Comparison & 22 & 4.86 & 0.89 & & \\
\hline \multirow{2}{*}{ Monogloss } & Treatment & 24 & 54.21 & 14.75 & \multirow{2}{*}{-1.858} & \multirow{2}{*}{0.070} \\
\hline & Comparison & 22 & 61.83 & 12.90 & & \\
\hline \multirow{2}{*}{ Heterogloss } & Treatment & 24 & 45.79 & 14.75 & \multirow{2}{*}{1.858} & \multirow{2}{*}{0.070} \\
\hline & Comparison & 22 & 38.17 & 12.90 & & \\
\hline \multirow{2}{*}{ Total contraction } & Treatment & 24 & 31.51 & 11.81 & \multirow{2}{*}{1.251} & \multirow{2}{*}{0.218} \\
\hline & Comparison & 22 & 27.29 & 11.00 & & \\
\hline \multirow{2}{*}{ Total expansion } & Treatment & 24 & 14.28 & 9.80 & \multirow{2}{*}{1.276} & \multirow{2}{*}{0.209} \\
\hline & Comparison & 22 & 10.88 & 8.11 & & \\
\hline \multirow{2}{*}{ DCo $^{1}$} & Treatment & 24 & 14.39 & 8.46 & \multirow{2}{*}{1.247} & \multirow{2}{*}{0.219} \\
\hline & Comparison & 22 & 11.51 & 7.06 & & \\
\hline \multirow{2}{*}{$\mathrm{E}$} & Treatment & 24 & 9.93 & 7.79 & \multirow{2}{*}{0.873} & \multirow{2}{*}{0.387} \\
\hline & Comparison & 22 & 8.09 & 6.39 & & \\
\hline
\end{tabular}

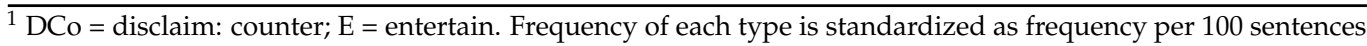

Mann-Whitney $U$ tests were conducted for the frequencies of stance subtypes in non-normal distribution. Results revealed that there was also no significant difference between the two groups. Table 5 provides the descriptive statistics of non-normal variables and results of Mann-Whitney $U$ tests.

Table 5. Descriptive statistics and Mann-Whitney $U$ tests of stance deployment between two groups in the pre-test.

\begin{tabular}{|c|c|c|c|c|c|c|}
\hline & Group & $N$ & $M$ & $S D$ & $z$ & $p$ \\
\hline \multirow{2}{*}{$\mathrm{DD}^{1}$} & Treatment & 24 & 3.49 & 4.50 & \multirow{2}{*}{1.227} & \multirow{2}{*}{0.220} \\
\hline & Comparison & 22 & 1.90 & 2.99 & & \\
\hline \multirow{2}{*}{ PC } & Treatment & 24 & 1.11 & 2.25 & \multirow{2}{*}{0.588} & \multirow{2}{*}{0.557} \\
\hline & Comparison & 22 & 1.97 & 3.76 & & \\
\hline \multirow{2}{*}{ PP } & Treatment & 24 & 9.73 & 7.24 & \multirow{2}{*}{0.386} & \multirow{2}{*}{0.700} \\
\hline & Comparison & 22 & 9.76 & 8.34 & & \\
\hline \multirow{2}{*}{ PE } & Treatment & 24 & 2.80 & 3.64 & \multirow{2}{*}{0.635} & \multirow{2}{*}{0.525} \\
\hline & Comparison & 22 & 2.15 & 3.46 & & \\
\hline \multirow{2}{*}{ A } & Treatment & 24 & 4.35 & 5.11 & \multirow{2}{*}{1.023} & \multirow{2}{*}{0.306} \\
\hline & Comparison & 22 & 2.79 & 4.18 & & \\
\hline
\end{tabular}

${ }^{1} \mathrm{DD}=$ disclaim: denial; $\mathrm{PC}=$ proclaim: concur; $\mathrm{PP}=$ proclaim: pronounce; $\mathrm{PE}$ = proclaim: endorse; $\mathrm{A}=$ attribute. Frequency of each type is standardized as frequency per 100 sentences.

Taken together, the statistical results revealed that the two groups were comparable prior to the writing intervention in terms of overall writing quality and stance deployment including stance scores, stance diversity, and frequencies of stance types. 


\subsection{Effects of Writing Instruction}

\subsubsection{Changes in Overall Writing Scores and Stance Scores Within and Between Groups}

A series of paired-samples $t$-tests were applied to compare the overall writing scores, the overall stance scores, M1 and M3 stance scores in the pre- and post-tests within each group. Results in Table 6 showed that both groups had significant improvement in terms of the overall writing scores, the overall stance scores, and M1 stance scores after the writing instruction they received, respectively. The effects of the gains were strong in the treatment group (Cohen's $d=1.177,1.313$, and 0.846), while the effects were around the medium level in the comparison group (Cohen's $d=0.681,0.497$, and 0.534). Students in the treatment group also had a significant improvement in M3 stance scores with a small effect size (Cohen's $d=0.423$ ). No significant change was detected for the comparison group in terms of M3 stance scores.

Table 6. Descriptive statistics and results of paired samples $t$-tests of writing scores within the groups.

\begin{tabular}{|c|c|c|c|c|c|c|c|c|}
\hline \multirow{2}{*}{ Group } & \multirow{2}{*}{ Writing Scores } & \multicolumn{2}{|c|}{ Pre-Test } & \multicolumn{2}{|c|}{ Post-Test } & \multirow{2}{*}{$t$} & \multirow{2}{*}{$p$} & \multirow{2}{*}{ Cohen's $d$} \\
\hline & & $M$ & $S D$ & $M$ & $S D$ & & & \\
\hline \multirow{5}{*}{$\begin{array}{l}\text { Treatment Group } \\
\qquad(n=24)\end{array}$} & Overall writing scores & 68.65 & 8.17 & 76.83 & 5.93 & 5.765 & $<0.001$ & 1.177 \\
\hline & Overall stance scores & 11.46 & 4.89 & 18.88 & 4.82 & 6.430 & $<0.001$ & 1.313 \\
\hline & M1 stance & 4.85 & 1.97 & 6.85 & 2.03 & 4.145 & $<0.001$ & 0.846 \\
\hline & M2 stance & 1.69 & 1.76 & 6.29 & 2.60 & & & \\
\hline & M3 stance & 4.92 & 2.90 & 5.73 & 1.89 & 2.072 & 0.050 & 0.423 \\
\hline \multirow{5}{*}{$\begin{array}{l}\text { Comparison } \\
\text { Group } \\
(n=22)\end{array}$} & Overall writing score & 65.36 & 8.36 & 68.16 & 7.76 & 3.192 & 0.004 & 0.681 \\
\hline & Overall stance score & 10.09 & 3.41 & 12.02 & 4.51 & 2.332 & 0.030 & 0.497 \\
\hline & M1 stance & 4.00 & 1.05 & 4.68 & 1.71 & 2.503 & 0.021 & 0.534 \\
\hline & M2 stance & 1.14 & .35 & 2.48 & 2.59 & & & \\
\hline & M3 stance & 4.95 & 2.53 & 4.86 & 1.98 & -0.238 & 0.814 & \\
\hline
\end{tabular}

Wilcoxon signed-rank tests were conducted for the comparisons of M2 stance scores within each group. Results revealed significant improvement of scores in the post-test than the pre-test for both the treatment group $(z=4.028, p<0.001, r=0.822)$ with a large effect size and the comparison group $(z=2.012, p=0.044, r=0.429)$ with a medium effect size.

Results of independent samples $t$-tests revealed significant differences in the post-test between the two groups with regard to the overall writing scores $(t(44)=4.282, p<0.001$, Cohen's $d=1.118)$, the overall stance scores $(t(44)=4.967, p<0.001$, Cohen's $d=1.520)$, and M1 stance scores $(t(44)=3.909, p<0.001$, Cohen's $d=1.272)$. This indicated that the treatment group outperformed the comparison group in the post-test with a large effect size on these three aspects. However, the two groups did not statistically differ in M3 stance scores, $t(44)=1.516, p=0.137$, Cohen's $d=0.438$. Results of Mann-Whitney $U$ tests further showed that students in the treatment group achieved significantly higher M2 stance scores $(M=6.29, S D=2.60)$ than students in the comparison group $(M=2.48$, $S D=2.59), U=96.00, z=3.792, p<0.001, r=0.559$, with a large effect size.

\subsubsection{Changes in Stance Deployment Within and Between Groups}

A series of paired-samples $t$-tests were applied to compare, within each group, the normally distributed variables of stance deployment, including stance diversity, frequencies of the general stance categories (i.e., total contraction, total expansion, monogloss, and heterogloss) and the frequency of disclaim: counter and of entertain. Table 7 presents the descriptive statistics and results of paired-samples $t$-tests. It can be noted that the treatment group had significant changes in terms of the frequency of total expansion $(t(21)=3.341$, $p=0.003$, Cohen's $d=0.682)$, heterogloss $(t(21)=3.050, p=0.006$, Cohen's $d=0.623)$, and monogloss $(t(21)=-3.050, p=0.006$, Cohen's $d=0.623)$ with a medium effect size 
after the writing intervention, while changes in other types were not significant. However, no significant changes were detected for these variables in the comparison group in the post-test.

Table 7. Descriptive statistics and paired samples $t$-tests of stance deployment within group.

\begin{tabular}{|c|c|c|c|c|c|c|c|c|}
\hline \multirow{2}{*}{ Group } & \multirow{2}{*}{ Variables } & \multicolumn{2}{|c|}{ Pre-Test } & \multicolumn{2}{|c|}{ Post-Test } & \multirow{2}{*}{$t$} & \multirow{2}{*}{$p$} & \multirow{2}{*}{ Cohen's $d$} \\
\hline & & $M$ & $S D$ & $M$ & $S D$ & & & \\
\hline \multirow{7}{*}{$\begin{array}{l}\text { Treatment Group } \\
\qquad(n=24)\end{array}$} & Stance diversity & 5.33 & 1.24 & 5.50 & 1.10 & 0.624 & 0.539 & \\
\hline & DCo $^{1}$ & 14.39 & 8.46 & 12.49 & 7.65 & -0.969 & 0.342 & \\
\hline & $\mathrm{E}$ & 9.93 & 7.79 & 13.58 & 9.93 & 1.641 & 0.114 & \\
\hline & Total contraction & 31.51 & 11.81 & 31.15 & 15.40 & -0.139 & 0.891 & \\
\hline & Total expansion & 14.28 & 9.80 & 23.82 & 13.49 & 3.341 & 0.003 & 0.682 \\
\hline & Monogloss & 54.21 & 14.75 & 45.02 & 19.07 & 3.050 & 0.006 & 0.623 \\
\hline & Heterogloss & 45.79 & 14.75 & 54.98 & 19.07 & -3.050 & 0.006 & 0.623 \\
\hline \multirow{7}{*}{$\begin{array}{l}\text { Comparison } \\
\text { Group } \\
(n=22)\end{array}$} & Stance diversity & 4.86 & .89 & 5.14 & 1.21 & -1.188 & 0.248 & \\
\hline & DCo & 11.51 & 7.06 & 11.28 & 6.92 & 0.172 & 0.865 & \\
\hline & $\mathrm{E}$ & 8.09 & 6.39 & 5.88 & 5.22 & 1.903 & 0.071 & \\
\hline & Total contraction & 27.29 & 11.00 & 29.36 & 12.03 & -1.366 & 0.186 & \\
\hline & Total expansion & 10.88 & 8.11 & 10.65 & 7.94 & 0.118 & 0.907 & \\
\hline & Monogloss & 61.83 & 12.90 & 59.99 & 16.63 & 0.976 & 0.340 & \\
\hline & Heterogloss & 38.17 & 12.90 & 40.01 & 16.63 & -0.976 & 0.340 & \\
\hline
\end{tabular}

${ }^{1} \mathrm{DCo}=$ disclaim: counter; $\mathrm{E}=$ entertain. Frequency of each type is standardized as frequencies per 100 sentences. This table only shows the variables in normal distribution.

Wilcoxon signed-rank tests were conducted for variables in non-normal distribution, including the frequency of disclaim: deny, proclaim: concur, proclaim: pronounce, proclaim: endorse, and attribute. Results in Table 8 revealed that after the writing intervention, the treatment group had significant changes in the frequency of proclaim: pronounce $(z=-2.294, p=0.022, r=0.468)$, proclaim: endorse $(z=-2.411, p=0.016, r=0.492)$, and attribute $(z=-3.070, p=0.002, r=0.627)$. The change in attribute was a large effect size and those for the other two types were in a medium level of effect size. No significant changes were found in the comparison group in the post-test.

A series of independent-samples $t$-tests were applied to compare the normally distributed variables of stance deployment in the post-test between the two groups, including stance diversity, the frequencies of the general stance categories (i.e., total contraction, total expansion, monogloss, and heterogloss), and the frequency of disclaim: counter and entertain. Results revealed that the frequency of entertain in treatment group was significantly higher than the comparison group, $t(44)=3.330, p=0.002$, Cohen's $d=1.476$. Students in the treatment group used more total expansion $(t(44)=4.075, p<0.001$, Cohen's $d=1.660)$ and heterogloss $(t(44)=2.826, p=0.007$, Cohen's $d=0.900)$ than students in the comparison group; at the same time, they applied fewer monogloss than their counterparts in the comparison group, $t(44)=-2.826, p=0.007$, Cohen's $d=0.900$. No significant difference was detected between the two groups in terms of stance diversity $(t(44)=1.068$, $p=0.292)$ and the frequency of disclaim: counter $(t(44)=0.560, p=0.578)$, and total contraction $(t(44)=0.438, p=0.664)$.

Mann-Whitney $U$ tests were performed to compare the frequencies of stance types that were in non-normal distribution between the two groups in the post-test, including disclaim: deny, proclaim: concur, proclaim: pronounce, proclaim: endorse and attribute. Results showed that the frequency of proclaim: pronounce in the treatment group was significantly lower than the comparison group, $U=152.50, z=2.470, p=0.014, r=0.364$, 
with a medium effect size. The frequency of attribute in the treatment group was significantly higher than the comparison group, $U=161.00, z=2.325, p=0.020, r=0.343$. While non-significant results were obtained in the comparisons of the frequency of disclaim: deny $(U=236.5, z=0.699, p=0.485)$, proclaim: concur $(U=252.00, z=0.310, p=0.756)$, and proclaim: endorse $(U=210.50, z=1.258, p=0.208)$. Figures 2 and 3 provide a visual summary of the comparisons of means of variables for stance deployment between the two groups in the post-test.

Table 8. Descriptive statistics and results of Wilcoxon signed-rank tests of stance deployment within the groups.

\begin{tabular}{|c|c|c|c|c|c|c|c|c|}
\hline \multirow{2}{*}{ Group } & \multirow{2}{*}{ Variables } & \multicolumn{2}{|c|}{ Pre-Test } & \multicolumn{2}{|c|}{ Post-Test } & \multirow{2}{*}{$z$} & \multirow{2}{*}{$p$} & \multirow{2}{*}{$r$} \\
\hline & & $M$ & $S D$ & $M$ & $S D$ & & & \\
\hline \multirow{5}{*}{ Treatment Group $(n=24)$} & $\mathrm{DD}^{1}$ & 3.49 & 4.50 & 4.07 & 6.25 & 0.659 & 0.510 & \\
\hline & PC & 1.11 & 2.25 & 2.48 & 3.68 & 1.491 & 0.136 & \\
\hline & $\mathrm{PP}$ & 9.73 & 7.24 & 6.77 & 7.91 & 2.294 & 0.022 & 0.468 \\
\hline & PE & 2.80 & 3.64 & 5.36 & 6.14 & 2.411 & 0.016 & 0.492 \\
\hline & A & 4.35 & 5.11 & 10.25 & 10.05 & 3.070 & 0.002 & 0.627 \\
\hline \multirow{5}{*}{ Comparison Group $(n=22)$} & DD & 1.90 & 2.99 & 1.89 & 2.88 & 0.059 & 0.953 & \\
\hline & PC & 1.97 & 3.76 & 2.25 & 3.74 & 0.169 & 0.866 & \\
\hline & $\mathrm{PP}$ & 9.76 & 8.34 & 11.15 & 6.38 & 0.893 & 0.372 & \\
\hline & $\mathrm{PE}$ & 2.15 & 3.46 & 2.78 & 3.31 & 0.296 & 0.767 & \\
\hline & $\mathrm{A}$ & 2.79 & 4.18 & 4.77 & 7.18 & 0.770 & 0.441 & \\
\hline
\end{tabular}

${ }^{1} \mathrm{DD}=$ disclaim: denial; $\mathrm{PC}$ = proclaim: concur; $\mathrm{PP}$ = proclaim: pronounce; $\mathrm{PE}=$ proclaim: endorse; $\mathrm{A}=$ attribute. Frequency of each type is standardized as frequency per 100 sentences. This table shows results of variables in non-normal distribution.

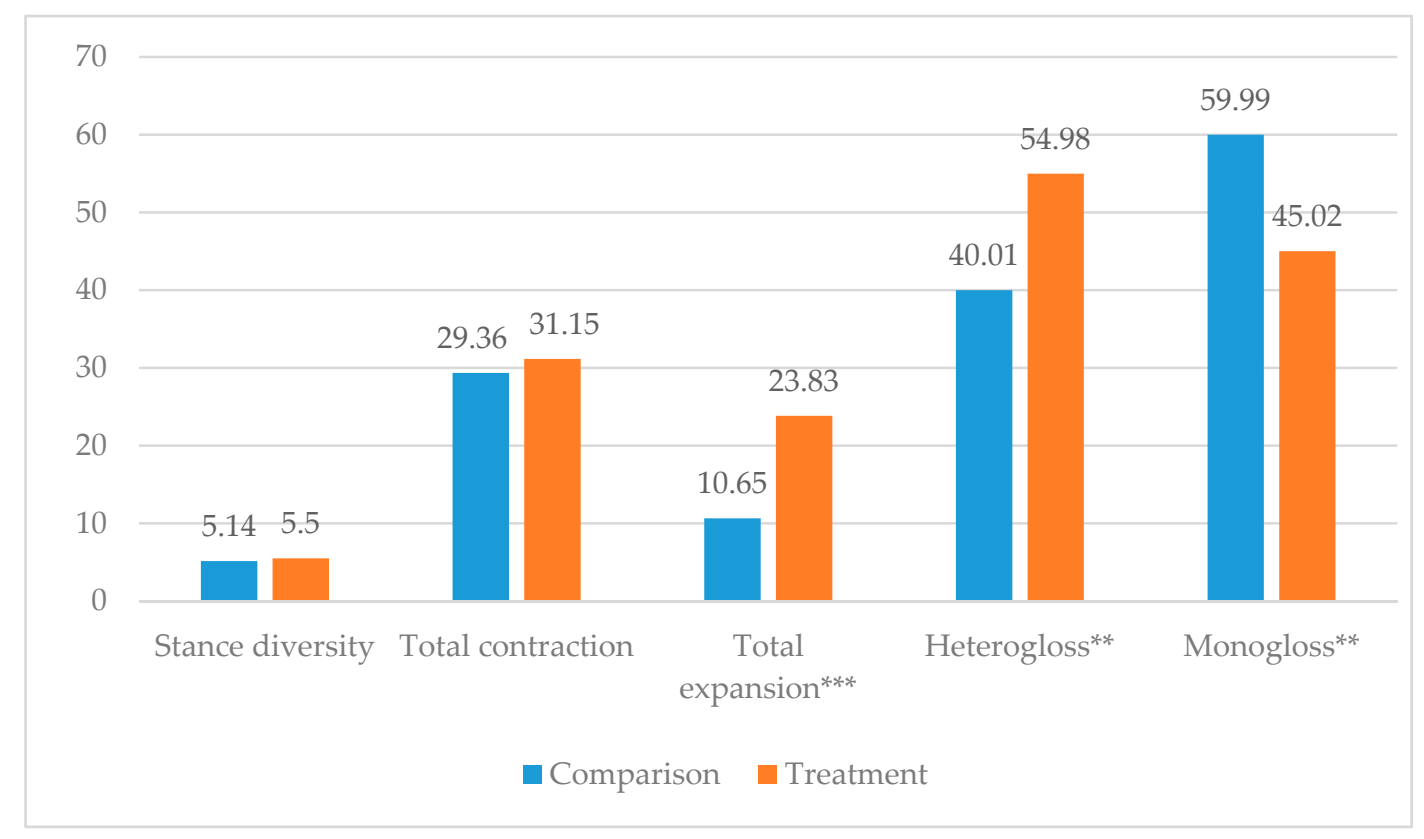

Figure 2. Comparisons of stance diversity and frequencies of general stance categories between groups in the post-test. ${ }^{* * *} p<0.001 ; * * p<0.01$. Frequency of each type is standardized as frequency per 100 sentences. 


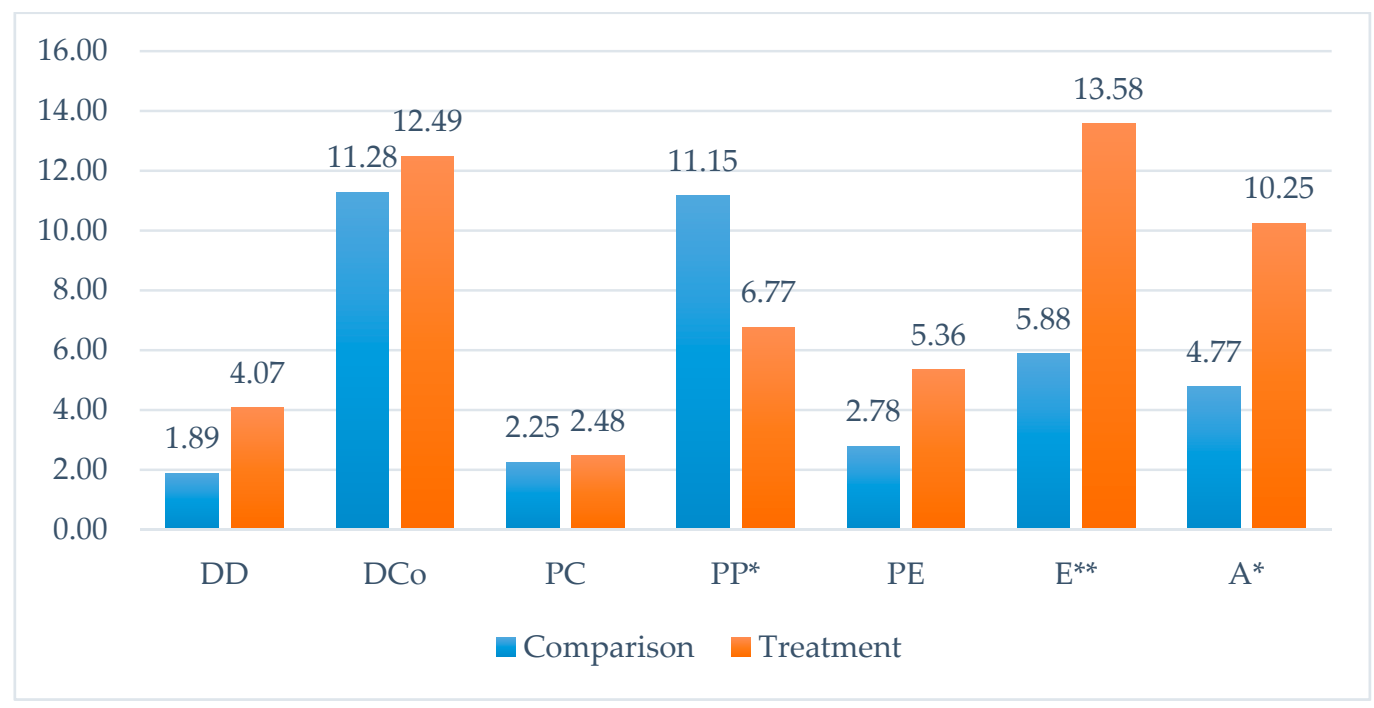

Figure 3. Comparisons of frequencies of stance subtypes between groups in the post-test. ${ }^{* *} p<0.01$; ${ }^{*} p<0.05$. DD $=$ disclaim: denial; $\mathrm{DCo}=$ disclaim: counter; $\mathrm{PC}=$ proclaim: concur; $\mathrm{PP}=$ proclaim: pronounce; $\mathrm{PE}=$ proclaim: endorse; $\mathrm{E}=\mathrm{entertain}$; $\mathrm{A}=$ attribute. Frequency of each type is standardized as frequency per 100 sentences.

\section{Discussion}

We examined the effects of explicit stance instruction and detected some positive results in terms of EFL students' stance deployment and academic writing quality. As a whole, students from the treatment group outperformed the comparison group in writing quality and stance performance after the writing intervention. They also showed changes in the deployment of various stance types in their writing.

\subsection{Effects on Overall Writing Quality and Stance Performance}

Regarding RQs 1 and 2, while the writing instruction in both groups provided some positive effects on students' writing quality and stance performance, the treatment group significantly outperformed the comparison group in terms of the overall writing scores, the overall stance scores, M1 and M2 stance scores in the post-test. This suggests that the writing intervention provided for the treatment group supported students to become better stance-takers who could achieve better academic writing outcomes, than the comparison group, who did not receive explicit stance instruction. From our finding, the writing intervention, with explicit rule explanation and exploration of authentic materials, aided students in effectively deploying stance features to fulfil rhetorical purposes of the academic genre and presenting convincing arguments for better writing quality. This finding aligns with previous studies that have shown that explicit instruction is effective for students' learning of stance in writing $[19,37]$.

It could also be noted that the M1 and M2 stance scores of the students in the comparison group also increased with a medium effect size. As the comparison group was also provided with the genre knowledge of introduction section, the gains in stance scores might be attributed to students' acquisition of the required rhetorical steps in introduction, rather than of improved stance deployment. This could be corroborated by the small magnitude of increase in stance scores, as well as the results of deployment of stance resources below.

\subsection{Effects on Stance Deployment}

Regarding RQ3 of the effects on stance deployment, no significant difference was found in students' stance diversity between the two groups in the post-test. This may be due to that as students had already applied multiple stance types in the pre-test (mean values of stance diversity in two groups were 5.33 and 4.86, respectively), during the writing intervention they might have put more effort into assessing and modifying the 
application of various stance types in their own writing. Their writing, therefore, may have exhibited changes in stance frequencies and nuanced configuration, rather than diversity. This echoes Crosthwaite and Jiang's [7] argument that students were capable of using a wide variety of stance devices, and the impact of instruction is to help them gain control over the academic discourse "via the use of a more careful, narrower, less polarizing, and less personal range of expressions" to convey their opinions (p. 102).

In terms of stance frequencies, student writers in the treatment group used significantly more heteroglossic and fewer monoglossic utterances than students in the comparison groups in the post-test. The heteroglossic growth largely came from students' increased use of expansive stances, as indicated by evidence of increased frequency of total expansion in students' writing. This indicates that students were able to produce an increased number of dialogically diverse propositions, especially in a dialogically expansive manner. The improvement is meaningful as the underuse of expansive stances was frequently found as a salient drawback in L2 and novice students' use of stance in writing $[9,15]$. The finding resonates with Crosthwaite and Jiang's [7] results that students had increased use of hedges after explicit instruction of stance. This suggests that the explicit stance instruction appeared to enhance students' understanding of the function of dialogically expansive stances and assist them in developing the competence of making tentative claims to show mitigation and establish reader solidarity.

With regard to stance subtypes, results firstly showed that students in the treatment group applied significantly more instances of entertain than students in the comparison group in the post-test. Formulations of entertain indicate that the author's position is one of a number of possibilities, which are typically represented by modal expressions (e.g., may, might) or appearance-based verbs (e.g., seem) [9]. This finding indicates that, for the treatment group, their writing encompassed more modal or circumstantial expressions to provide dialogic space for alternatives. After the intervention, it seems that the students possessed increased awareness of the importance of providing space for dialogic possibilities, through noticing the use of modality in the learning materials or from teacher's explicit explanations.

The frequency of attribute, another type of dialogic expansion, was also found to be statistically higher in the writing from the treatment group than the comparison group in the post-test. According to Martin and White [30], formulations of attribution disassociate the proposition from the authorial voice by attributing it to external sources. Moreover, the frequency of another type of stance concerning external sources, proclaim: endorse, also significantly increased within the treatment group in the post-test. These findings altogether suggest that students were more aware of the necessity to include external voices and increasingly construe sourced propositions to support argumentation. It could also be noticed that the frequency of attribute $(M=10.25)$ almost doubled that of proclaim: endorse $(M=5.36)$ in the post-test writing from the treatment group. Martin and White [30] explained that endorsed formulations construe the sourced propositions by the internal authorial voice as "maximally warrantable" (p. 126). This finding thus suggests that when dealing with external sources, students were more willing to keep distance from the attributed material than to take authorial responsibility for the endorsed proposition. Although students put more endeavor to invite external sources after the writing intervention, they were cautious about taking authorial responsibility and preferred to stay authorially detached. This finding aligns with Lee and Deakin's [3] finding that Chinese ESL students resisted taking a strong writer identity and preferred to maintain a detached writing style. It also corroborates Lee et al.'s [59] finding that, in L2 undergraduates' citation practices, students primarily used source texts for an attribution function and tended to adopt a non-committal stance that acknowledges or distances themselves from cited sources. This could be due to students' lack of confidence in the validity of source materials, or their self-perceived peripheral status in the academic discipline, or their traditional Chinese values of collectivism [22]. Thus, explicit stance instruction alone might pose limited impact on the way students include external sources. 
Results also indicated that after the writing intervention, students from the treatment group exhibited a significant drop in the application of proclaim: pronounce; the frequency was found to be lower, statistically significantly, than the comparison group in the posttest. Martin and White [30] pointed out that formulations of proclaim: pronounce involve explicit authorial interpolations to assert upon the credibility of the proposition with a more subjective voice, which may pose a threat to reader solidarity. This finding thus indicates that student writers in the treatment group deployed fewer subjective voices when assert the validity of propositions, which may contribute to better alignment with the reader and enhance writing quality. This is consistent in a way with Crosthwaite and Jiang's [7] finding that students showed an overall reduction in the use of self-mention after explicit stance instruction, indicating that they were less personal when stamping their authority on the construed claims. We thus posit that explicit stance instruction fostered students with a better understanding of the dialogic effects of various stance types, helped them develop the necessary competence and repertoire for more appropriate academic writing.

\section{Conclusions and Implications}

This quasi-experimental intervention study was conducted to examine the effects of explicit stance instruction on EFL students' stance deployment and academic writing quality. The successful application of the Engagement system in the writing intervention provides practical evidence for its applicability as a pedagogical affordance. As a number of scholars have advocated, there is a concerted need for explicit instruction in authorial stance in writing classroom $[2,7,13,18,19]$. Our study provides further empirical support for the effectiveness of explicit instruction to enhance student writers' understanding and deployment of stance, as well as boost their overall academic writing quality. After the intervention completed, students exhibited progress in an array of the commonly found challenges concerning stance-taking, such as single-voiced, subjective, and underuse of expansive stances. However, it was also found that the intervention had limited influence on students' regulation of external voices, which means additional teaching affordance is needed to scaffold students in this aspect, such as through increased input of source materials. At the level of course design, our findings suggest that incorporating Engagement-based explicit stance instruction into academic writing classrooms could facilitate students' development of stance-taking skills, which will sustainably benefit their academic writing and future scholarship.

Informed by the current research findings, several pedagogical practices could be recommended. Firstly, the current findings suggest that teachers should pay more attention to elucidating the dialogic and interactive nature of writing. Instruction on the dialogic functions of various stance resources could be useful in raising students' awareness of why and how to use stance features strategically to improve academic writing quality. Authentic texts could be a valuable assist for students to make sense of individual stance meaning within context and to notice the flow of stance features in discourse. Secondly, we would recommend that stance instruction complemented by genre knowledge may be fruitful in raising students' awareness of achieving rhetorical purposes and communicative functions through appropriate deployment of stance resources. In addition, it is also important for teachers to provide consistent feedback on the appropriateness of students' stance endeavors, to make stance features more visible for them as they attempt to take stances in their own writing [60]. As Lee and Deakin [3] pointed out, this may help students "mark their stance more mindfully and engage with readers more meaningfully" in their own writing (p. 32).

There are some limitations of the current study. One is that we only recruited thirdyear English majors from one medium-ranking university in China. Future studies could be conducted to examine the effectiveness of intervention with participants at different proficiency levels or in different contexts. Another limitation is that, due to practical considerations, the current research used after-class assignments for collecting written texts and allowed students to decide their own topic. Thus, the writing scores may not 
reliably represent students' academic writing competence, as it may be influenced by time allocation or topic differences. Future studies thus could investigate stance-taking performance in timed academic writing tasks in class. Additionally, although positive results were obtained, the current research examined only the short-term effectiveness of explicit stance instruction by using pre- and post-tests, and the sample size of each group was relatively small. Further intervention studies could be conducted to examine the long-term effects of instruction with more participants to observe the maintenance of the stance gains by including delayed post-tests, to provide richer data on, and more insights into, the effects of explicit stance instruction on fostering students' stance-taking skills for the sustainable goal of developing their academic writing ability.

Author Contributions: L.Z. and L.J.Z. conceived and designed the study. L.Z. collected the data and drafted the manuscript and all the authors revised the manuscript. L.J.Z. finalized it for submission as the corresponding author. All authors have read and agreed to the published version of the manuscript.

Funding: This research received no external funding.

Institutional Review Board Statement: The study involving human participants was reviewed and approved by the Human Participants Ethics Committee of The University of Auckland (019807, 15 September 2017).

Informed Consent Statement: Informed consent was obtained from all subjects involved in the study.

Data Availability Statement: The data presented in this study are available on request from the corresponding author. The data are not publicly available due to ethical considerations.

Conflicts of Interest: The authors declare no conflict of interest.

\section{Appendix A}

Table A1. Stance Rating Scale.

\begin{tabular}{|c|c|c|}
\hline Score & Level & Criteria \\
\hline \multirow{3}{*}{ Move 1} & $10-8$ & $\begin{array}{l}\text { Mixture of monogloss and heterogloss to give background; Use endorse or attribute to establish } \\
\text { research field; Use entertain to suggest possibility; Use counter. }\end{array}$ \\
\hline & $7-4$ & $\begin{array}{c}\text { More monogloss than heterogloss to give background; Use counter; Limited endorse or attribute; } \\
\text { Limited entertain; Or obscure establishment of research field. }\end{array}$ \\
\hline & $3-1$ & $\begin{array}{c}\text { Monogloss dominant; Less or no heterogloss; Fact-reporting or narrative-like; No endorse or attribute; } \\
\text { No entertain; Or Move } 1 \text { absent. }\end{array}$ \\
\hline \multirow{3}{*}{ Move 2} & $10-8$ & $\begin{array}{c}\text { Clear indication of research gaps; Heterogloss more than monogloss; Use counter or deny; Less or no } \\
\text { pronounce; Use endorse or attribute. }\end{array}$ \\
\hline & $7-4$ & Obscure indication of research gaps; Limited heterogloss; Use pronounce; Less or no counter or deny. \\
\hline & $3-1$ & Monogloss dominant; Use pronounce; Or Move 2 absent. \\
\hline \multirow{3}{*}{ Move 3} & $10-8$ & Monogloss dominant; Clear description of the research goal or structure. \\
\hline & $7-4$ & $\begin{array}{c}\text { Dense or obscure description of the research goal or structure; Use pronounce; Monogloss more } \\
\text { than heterogloss. }\end{array}$ \\
\hline & $3-1$ & Move 3 under-developed or absent. \\
\hline
\end{tabular}




\section{Appendix B}

Table A2. Stance Coding Scheme.

\begin{tabular}{|c|c|c|c|c|}
\hline Stance Types & & & Type Description & $\begin{array}{l}\text { Examples of } \\
\text { Linguistic } \\
\text { Markers }\end{array}$ \\
\hline Monogloss & & & $\begin{array}{l}\text { Make no reference to other } \\
\text { voices; state facts or actions }\end{array}$ & \\
\hline \multirow{7}{*}{ Heterogloss } & \multirow{5}{*}{ 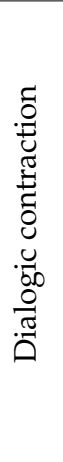 } & disclaim: deny (DD) & directly reject, negate & not, never, few, lack of \\
\hline & & $\begin{array}{l}\text { disclaim: counter } \\
\text { (DCo) }\end{array}$ & counter expectation, replace & $\begin{array}{l}\text { but, however, only, still, } \\
\text { on the contrary }\end{array}$ \\
\hline & & proclaim: concur $(\mathrm{PC})$ & $\begin{array}{l}\text { overly announce the reader as } \\
\text { agreeing with or having the } \\
\text { same knowledge }\end{array}$ & $\begin{array}{l}\text { obviously, undoubtedly, } \\
\text { as we all know }\end{array}$ \\
\hline & & $\begin{array}{l}\text { proclaim: pronounce } \\
\text { (PP) }\end{array}$ & $\begin{array}{l}\text { explicit author intervention; } \\
\text { intensifiers }\end{array}$ & $\begin{array}{l}\text { indeed, really, must, quite, } \\
\text { greatly, especially, most }\end{array}$ \\
\hline & & proclaim: endorse (PE) & $\begin{array}{l}\text { refer to external sources as } \\
\text { correct }\end{array}$ & $\begin{array}{l}\text { X proves/shows } \\
\text { X finds/points out }\end{array}$ \\
\hline & \multirow{2}{*}{ 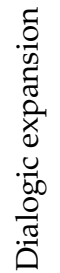 } & entertain $(E)$ & $\begin{array}{l}\text { proposition as one of possible } \\
\text { positions; allow room for } \\
\text { multiple voices }\end{array}$ & $\begin{array}{l}\text { may, possible, seem, tend to, } \\
\text { could, generally, often, } \\
\text { in my opinion }\end{array}$ \\
\hline & & attribute $(\mathrm{A})$ & $\begin{array}{c}\text { refer to external sources } \\
\text { without displaying an attitude } \\
\text { towards it }\end{array}$ & $\begin{array}{l}\text { According to } Y \\
\text { Y says/suggests } \\
\text { It is said that }\end{array}$ \\
\hline
\end{tabular}

\section{References}

1. Crosthwaite, P.; Cheung, L.; Jiang, F.K. Writing with attitude: Stance expression in learner and professional dentistry research reports. Engl. Specif. Purp. 2017, 46, 107-123. [CrossRef]

2. Hyland, K. Stance and engagement: A model of interaction in academic discourse. Discourse Stud. 2005, 7, 173-192. [CrossRef]

3. Lee, J.J.; Deakin, L. Interactions in L1 and L2 undergraduate student writing: Interactional metadiscourse in successful and less-successful argumentative essays. J. Second Lang. Writ. 2016, 33, 21-34. [CrossRef]

4. Wharton, S. Epistemological and interpersonal stance in a data description task: Findings from a discipline-specific learner corpus. Engl. Specif. Purp. 2012, 31, 261-270. [CrossRef]

5. Aull, L.L.; Bandarage, D.; Miller, M.R. Generality in student and expert epistemic stance: A corpus analysis of first-year, upper-level, and published academic writing. J. Engl. Acad. Purp. 2017, 26, 29-41. [CrossRef]

6. Cheng, F.-W.; Unsworth, L. Stance-taking as negotiating academic conflict in applied linguistics research article discussion sections. J. Engl. Acad. Purp. 2016, 24, 43-57. [CrossRef]

7. Crosthwaite, P.; Jiang, F.K. Does EAP affect written L2 academic stance? A longitudinal learner corpus study. System 2017, 69, 92-107. [CrossRef]

8. Hyland, K.; Jiang, F.K. Change of attitude? A diachronic study of stance. Writ. Commun. 2016, 33, 251-274. [CrossRef]

9. Lancaster, Z. Exploring valued patterns of stance in upper- level student writing in the disciplines. Writ. Commun. 2014, 31, 27-57. [CrossRef]

10. Loi, C.K.; Lim, J.M.H.; Wharton, S. Expressing an evaluative stance in English and Malay research article conclusions: International publications versus local publications. J. Engl. Acad. Purp. 2016, 21, 1-16. [CrossRef]

11. Wingate, U. 'Argument!' helping students understand what essay writing is about. J. Engl. Acad. Purp. 2012, 11, 145-154. [CrossRef]

12. Zhao, C.G. Voice in timed L2 argumentative essay writing. Assess. Writ. 2017, 31, 73-83. [CrossRef]

13. Li, T.; Wharton, S. Metadiscourse repertoire of L1 Mandarin undergraduates writing in English: A cross-contextual, crossdisciplinary study. J. Engl. Acad. Purp. 2012, 11, 345-356. [CrossRef]

14. Sawaki, T. On the function of stance-neutral formulations: Apparent neutrality as a powerful stance constructing resource. J. Engl. Acad. Purp. 2014, 16, 81-92. [CrossRef]

15. Hyland, K. Undergraduate understandings: Stance and voice in final year reports. In Stance and Voice in Written Academic Genres; Hyland, K., Sancho Guinda, C., Eds.; Palgrave Macmillan: New York, NY, USA, 2012; pp. 134-150. 
16. Wu, S.M. The use of engagement resources in high- and low-rated undergraduate geography essays. J. Engl. Acad. Purp. 2007, 6, 254-271. [CrossRef]

17. Chang, P. EFL doctoral students' conceptions of authorial stance in academic research writing: An exploratory study. RELC J. 2016, 47, 175-192. [CrossRef]

18. Chang, P.; Schleppegrell, M. Taking an effective authorial stance in academic writing: Making the linguistic resources explicit for L2 writers in the social sciences. J. Engl. Acad. Purp. 2011, 10, 140-151. [CrossRef]

19. Chang, P.; Schleppegrell, M. Explicit learning of authorial stance-taking by L2 doctoral students. J. Writ. Res. 2016, 8, 49-80. [CrossRef]

20. Cumming, A.; Lai, C.; Cho, H. Students' writing from sources for academic purposes: A synthesis of recent research. J. Engl. Acad. Purp. 2016, 23, 47-58. [CrossRef]

21. Cumming, A.; Yang, L.; Qiu, C.; Zhang, L.; Ji, X.; Wang, J.; Lai, C. Students' practices and abilities for writing from sources in English at universities in China. J. Second Lang. Writ. 2018, 39, 1-15. [CrossRef]

22. Xie, J. Direct or indirect? Critical or uncritical? Evaluation in Chinese English-major MA thesis literature reviews. J. Engl. Acad. Purp. 2016, 23, 1-15. [CrossRef]

23. Lee, S.H. An integrative framework for the analyses of argumentative/persuasive essays from an interpersonal perspective. Text Talk 2008, 28, 239-270. [CrossRef]

24. Miller, R.T.; Mitchell, T.D.; Pessoa, S. Valued voices: Students' use of engagement in argumentative history writing. Linguist. Educ. 2014, 28, 107-120. [CrossRef]

25. Bakhtin, M.M. The Dialogic Imagination: Four Essays; University of Texas Press: Austin, TX, USA, 1981.

26. Xu, L.; Zhang, L.J. L2 doctoral students' experiences in thesis writing in an English-medium university in New Zealand. J. Engl. Acad. Purp. 2019, 41, 1-13. [CrossRef]

27. White, P.R.R. Beyond modality and hedging: A dialogic view of the language of intersubjective stance. Text 2003, 23, 259-284. [CrossRef]

28. Du Bois, J.W. The stance triangle. In Stancetaking in Discourse: Subjectivity, Evaluation, Interaction; Englebretson, R., Ed.; Benjamins: Amsterdam, The Netherlands, 2007; pp. 139-182.

29. Chang, P. Using a stance corpus to learn about effective authorial stance-taking: A textlinguistic approach. ReCALL 2012, 24, 209-236. [CrossRef]

30. Martin, J.R.; White, P.R.R. The Language of Evaluation: Appraisal in English; Palgrave Macmillan: New York, NY, USA, 2005.

31. Ryshina-Pankova, M. Exploring academic argumentation in course-related blogs through ENGAGEMENT. In Evaluation in Context; Thompson, G., Alba-Juez, L., Eds.; Benjamins: Philadelphia, IL, USA, 2014; pp. 281-302.

32. Coffin, C.; Hewings, A.; North, S. Arguing as an academic purpose: The role of asynchronous conferencing in supporting argumentative dialogue in school and university. J. Engl. Acad. Purp. 2012, 11, 38-51. [CrossRef]

33. Humphrey, S.; MacNaught, L. Functional language instruction and the writing growth of English language learners in the middle years. TESOL Q. 2016, 50, 792-816. [CrossRef]

34. Lee, S.H. Command strategies for balancing respect and authority in undergraduate expository essays. J. Engl. Acad. Purp. 2010, 9, 61-75. [CrossRef]

35. Ho, V.; Li, C. The use of metadiscourse and persuasion: An analysis of first year university students' timed argumentative essays. J. Engl. Acad. Purp. 2018, 33, 53-68. [CrossRef]

36. Mu, C.; Zhang, L.J.; Ehrich, J.; Hong, H. The use of metadiscourse for knowledge construction in Chinese and English research articles. J. Engl. Acad. Purp. 2015, 20, 135-148. [CrossRef]

37. Fordyce, K. The differential effects of explicit and implicit instruction on EFL learners' use of epistemic stance. Appl. Linguist. 2014, 35, 6-28. [CrossRef]

38. Schmidt, R.W. The role of consciousness in second language learning. Appl. Linguist. 1990, 11, 129-158. [CrossRef]

39. Norris, J.M.; Ortega, L. Effectiveness of L2 instruction: A research synthesis and quantitative meta-analysis. Lang. Learn. 2000, 50, 417-528. [CrossRef]

40. Beck, S.W. Subjectivity and intersubjectivity in the teaching and learning of writing. Res. Teach. Engl. 2006, 40, 413-460. Available online: https://www.jstor.org/stable/40171710 (accessed on 6 May 2020).

41. Chandrasegaran, A. The effect of a socio-cognitive approach to teaching writing on stance support moves and topicality in students' expository essays. Linguist. Educ. 2013, 24, 101-111. [CrossRef]

42. Pessoa, S.; Mitchell, T.D.; Miller, R.T. Scaffolding the argument genre in a multilingual university history classroom: Tracking the writing development of novice and experienced writers. Engl. Specif. Purp. 2018, 50, 81-96. [CrossRef]

43. Takahashi, S. Assessing learnability in second language pragmatics. In Pragmatics across Languages and Cultures; Trosborg, A., Ed.; De Gruyter: Berlin, Germany, 2010; pp. 391-422.

44. Chen, Y.S.; Su, S.W. A genre-based approach to teaching EFL summary writing. ELT J. 2012, 66, 184-192. [CrossRef]

45. Cheng, A. Analyzing genre exemplars in preparation for writing: The case of an L2 graduate student in the ESP genre-based instructional framework of academic literacy. Appl. Linguist. 2008, 29, 50-71. [CrossRef]

46. Huang, J.C. Learning to write for publication in English through genre-based pedagogy: A case in Taiwan. System 2014, 45, 175-186. [CrossRef]

47. Hyland, K. Genre pedagogy: Language, literacy and L2 writing instruction. J. Second Lang. Writ. 2007, 16, 148-164. [CrossRef] 
48. Swales, J.M. Research Genres: Explorations and Applications; Cambridge University Press: New York, NY, USA, 2004.

49. Charles, M. Reconciling top-down and bottom-up approaches to graduate writing: Using a corpus to teach rhetorical functions. J. Engl. Acad. Purp. 2007, 6, 289-302. [CrossRef]

50. Uccelli, P.; Dobbs, C.L.; Scott, J. Mastering academic language: Organization and stance in the persuasive writing of high school students. Writ. Commun. 2013, 30, 36-62. [CrossRef]

51. Swales, J.M.; Feak, C.B. Academic Writing for Graduate Students: Essential Tasks and Skills, 3rd ed.; University of Michigan Press: Ann Arbor, MI, USA, 2012.

52. Del Saz Rubio, M.M. A pragmatic approach to the macro-structure and metadiscoursal features of research article introductions in the field of agricultural sciences. Engl. Specif. Purp. 2011, 30, 258-271. [CrossRef]

53. Buckley, E.; Cowap, L. An evaluation of the use of Turnitin for electronic submission and marking and as a formative feedback tool from an educator's perspective. Br. J. Educ. Technol. 2013, 44, 562-570. [CrossRef]

54. Dahl, S. Turnitin: The student perspective on using plagiarism detection software. Act. Learn. Higher Educ. 2007, 8, 173-191. [CrossRef]

55. Jacobs, H.L.; Zinkgraf, S.A.; Wormuth, D.R.; Hartfiel, V.F.; Hughey, J.B. Testing ESL Composition: A Practical Approach; Newbury House: Rowley, MA, USA, 1981.

56. Cohen, J. Statistical Power Analysis for the Behavioral Sciences, 2nd ed.; Erlbaum: Hillsdale, NJ, USA, 1988.

57. Cohen, J. A power primer. Psychol. Bull. 1992, 112, 155-159. [CrossRef] [PubMed]

58. Field, A. Discovering Statistics Using IBM SPSS Statistics, 4th ed.; Sage: Los Angeles, CA, USA, 2013.

59. Lee, J.J.; Hitchcock, C.; Elliott Casal, J. Citation practices of L2 university students in first-year writing: Form, function, and stance. J. Engl. Acad. Purp. 2018, 33, 1-11. [CrossRef]

60. Zhang, L.J.; Zhang, D. Dialogic discussion as a platform for constructing knowledge: Student-teachers' interaction patterns and strategies in learning to teach English. Asian-Pac. J. Second Foreign Lang. Educ. 2020, 5, 1-24. [CrossRef] 